\title{
The (Virtue) Epistemology of Political Ignorance*
}

\begin{abstract}
One typical aim of responsibilist virtue epistemology is to employ the notion of intellectual virtue in pursuit of an ameliorative epistemology. This paper focuses on "political inquiry" as a case study for examining the ameliorative value of intellectual virtue. The main claim is that the case of political inquiry threatens to expose responsibilist virtue epistemology in a general way as focusing too narrowly on the role of individual intellectual character traits in attempting to improve our epistemic practices.
\end{abstract}

\section{Introduction}

A central project of responsibilist virtue epistemology (RVE) is to develop "maps" or "perspicuous representations" of intellectual virtues, such as intellectual humility, intellectual courage, open-mindedness, and curiosity. The basic idea is to develop empirically grounded characterizations of epistemically admirable or praiseworthy individual character traits and to use these characterizations as guidance in an ameliorative epistemology, sometimes with the aim of informing education theory.

To take a few examples, Jason Baehr characterizes the "open-minded" person as someone who is "willing...to transcend a default cognitive standpoint in order to...take

\footnotetext{
* Thanks to Marc-Kevin Daoust, Paul Dimmock, Julien Dutant, Sebastian Köhler, Clayton Littlejohn, Francesco Praolini, Mona Simion, Lani Watson, and audience members at the Canadian Philosophical Association Annual Congress 2018, Université du Québec à Montréal, the European Epistemology Network Meeting 2018, VU Amsterdam, the Social Epistemology and Epistemic Normativity: Themes from Sandy Goldberg Workshop, Cardiff University, and the First Flemish Epistemology Workshop, KU Leuven. Special thanks to Jeroen de Ridder and Steven Bland for extensive feedback on earlier drafts of this paper. This research was conducted with the help of a Brandon University Research Committee New Faculty Research Grant.
} 
seriously a distinct cognitive standpoint" $(2011,152)$. Heather Battaly characterizes the "epistemically humble" person as someone who is "disposed to recognize her own fallibility, and to recognize and value the epistemic abilities of others..." (Battaly 2014, 194). James Montmarquet characterizes the "epistemically courageous" person as someone who has the disposition to "persevere in the face of opposition from others (until one is convinced that one is mistaken)..." (Montmarquet 1993, 23). And Roberts and Wood characterize the "epistemically autonomous" person as someone who has the "proper ability to think for herself and not be... improperly dependent on or influenced by others" (Roberts \& Wood 2007, 259).

In many ways, this work is an exciting new development in epistemology. It highlights possible avenues for widening the traditional epistemological project. It reveals some of the complex ways in which epistemology and ethics seem to overlap. It also raises numerous questions. For example, what is the relationship between the intellectual and moral virtues? What is the relationship between intellectual virtue and knowledge? What about truth? These and related questions have been discussed in depth in recent years (Zagzebski 1996; Greco 2010; Simion et. al forthcoming). Another set of questions, which has received less attention, concerns the ameliorative value of the mapping project: can and should we really try to improve the intellectual character of individuals? To what extent? And in what sorts of contexts?

These latter questions are the starting point of the present paper. I will focus as a case study on the context of political inquiry, the acquisition of political knowledge. Researchers in political science, economics, and public choice theory have amassed a large amount of evidence that suggests citizens of large representative democracies are decidedly 
not very good at learning about, and staying informed about, political issues. I'm interested in the extent to which trying to improve individuals' intellectual character is a way of promoting knowledge acquisition in this context. My main claim is that the case of political inquiry threatens to expose RVE in a general way as focusing too narrowly on the role of individual intellectual virtue in attempting to improve our epistemic practices.

To be sure, there are other reasons to be pessimistic about the role of intellectual virtues in ameliorative epistemology. Perhaps most centrally, RVE has come under attack for theorizing with tools that are too loosely connected to the truth (Greco 2010, Carter and Gordon 2014, Montmarquet 1987, Madison 2017, Rowbottom 2011; cf. Kwong 2017). However, as we'll see in more detail below, one of the interesting things about the context of political inquiry is that it seems like an especially good case for RVE. Indeed, it is increasingly common to hear discussion of the need for greater open-mindedness, conscientiousness, and intellectual autonomy amongst citizens in political discourse. What the present paper adds to more ordinary forms of pessimism about RVE is the claim that RVE is in trouble even in an especially promising case.

Here is the plan. Section 2 draws a preliminary distinction situating this paper within a body of related work already being done by proponents of RVE. Section 3 introduces some empirical research on political knowledge and explains why this looks like fertile ground for the ameliorative aims of RVE. Section 4 offers some reasons for pessimism about the ameliorative value of individual intellectual virtue in this context. Section 5 turns to some positive suggestions for developing a framework that also focuses on non-agent-centered ways of promoting knowledge acquisition. Section 6 takes a step 
back and presents two arguments for the claim that the context of political inquiry is an especially interesting and important case study for RVE. Section 7 concludes.

\section{Varieties of Non-Agent Centered Epistemology}

Proponents of RVE already tend to emphasize the importance of non-agent centered considerations in an ameliorative epistemology. For example, consider work being done at the intersection of virtue epistemology and education theory (Baehr forthcoming; Battaly 2013; Kidd 2015; Pritchard 2015; Tanesini 2016; Watson 2015). Surely such work is nonagent-centered, in the sense that education is a social and institutional practice. To help sharpen my focus, let me distinguish between two ways ameliorative epistemology can be "non-agent-centered."

First, ameliorative epistemology can be non-agent centered in a causal sense. An ameliorative epistemology is causally non-agent-centered to the extent that it focuses on the role that social and environmental factors play in making individuals better at knowledge acquisition. The paradigm example is education, but we might also include things like public service programs, and other structural elements of communities. ${ }^{1}$

\footnotetext{
${ }^{1}$ Much RVE is non-agent-centered in this sense. A recent paper by Heather Battaly argues that "the role of the self in character development and rehabilitation is not as exalted as we might have thought...[her] hope is that we will explore ways to design environments so that they support the development of virtues and the erosion of vices" (Battaly 2016, 221). Discussing the notion of "epistemic corruption", Ian Kidd argues "epistemic corruption occurs when an agent comes to develop or exercise one or more epistemic vices due their interaction with a social environment" (Kidd 2018). Jason Baehr recently helped found an actual school - the Intellectual Virtues Academy of Long Beach — that focuses specifically on educating for virtues (http://www.ivalongbeach.org/). Numerous edited volumes and special issues have been dedicated to questions surrounding the acquisition of intellectual virtue, the rehabilitation of intellectual vice, and the role of social and environmental factors in those processes (Baehr 2016; Fairweather \& Flanigan 2014).
} 
Second, ameliorative epistemology can be non-agent centered in a constitutive sense. An ameliorative epistemology is constitutively non-agent-centered to the extent that it focuses on the role that social and environmental factors play in individuals' knowledge acquisition. Here, the role of the individual in their own knowledge acquisition shares a seat with, or perhaps even takes a back seat to, the role that structural elements of environments, institutions and other social relations themselves play in promoting knowledge acquisition in individuals. An example of such a constitutive structural impact on knowledge acquisition might be how personalized search algorithms on internet browsing affect the way individuals acquire information. Focusing on such algorithmsfor example by engaging with regulation issues - might be one way an ameliorative epistemology could exhibit a non-agent-centered element in the constitutive sense.

There are ways structural and social factors can impact knowledge acquisition which seem to fit uneasily on either side of this distinction. For example, studies have suggested that better lighting in classrooms improves student performance (Veitch \& McColl 2001). Perhaps greater exposure to natural sunlight can play a causal role in making individuals become better inquirers (during the education process, for example). But perhaps it can also play a constitutive role in individuals' epistemic abilities under certain circumstances. It is beyond the scope of this paper to get into a detailed discussion of the metaphysics of the present distinction. It is enough to point out that an epistemology aiming at promoting individuals' epistemic abilities, whether through social and institutional means or otherwise, may nevertheless count as agent-centered in my constitutive sense. Acknowledging the causal importance of social and structural factors in promoting 
knowledge acquisition is not yet to acknowledge the constitutive importance of social and structural factors in promoting knowledge acquisition.

Unless stated otherwise, when I talk about non-agent-centered ways of promoting knowledge acquisition, I will mean constitutively non-agent-centered. ${ }^{2}$

\section{Political Ignorance}

What exactly is political knowledge? Start with the idea of a political belief:

Political belief: Any belief that is of direct relevance to decision making on political issues (such as whether to increase the national deficit, foreign aid, or to have public health care) ${ }^{3}$

\footnotetext{
${ }^{2}$ Others have pursued a broadly similar topic in different contexts. Perhaps most closely related, Elizabeth Anderson (2015) argues that epistemic justice (cf. Fricker 2007) is a virtue of social institutions. Roughly, her claim is that certain kinds of individual biases are epistemically neutral, or perhaps even epistemically useful, in certain contexts. But under the right social circumstances, they can become "vectors for epistemic injustice". Thus, her aim is to make a friendly addition to Fricker's framework (it should be noted that Fricker is herself aware of the potential need for such additions), and claims that properly engaging with problems of epistemic injustice requires engaging with social mechanisms at the institutional level. Relatedly, but more specifically focused on "de-biasing strategies", Tim Kenyon (2014) argues that "false polarization bias" can only adequately be mitigated at an institutional level; expecting individuals to be able to monitor and adjust themselves for false polarization tendencies are (hopelessly) unrealistic. Most radically, Sally Haslanger (2015) has argued that the very project of social critique (engaging with social injustice issues such as racism, sexism, and the like) should not be particularly concerned with individual biases. Rather, structural factorssuch as allocation of resources, and parental leave policies in the workplace-are the "primary source" of social injustice. Below I will draw on some of these writers' examples and positive suggestions.

${ }^{3}$ The boundaries of what counts as a political belief will be vague and broad. But there are nevertheless clearcut examples (such as those listed above). A fuller treatment this issue would grapple with the prospect of making a principled delineation. For example, it seems plausible that a normative component could be added to the above definition. That is to say, it seems plausible that political beliefs are those that should (in some sense) be of direct relevance to one's political decision making. This issue would take us too far afield.
} 
By "decision making on political issues" I mean decisions such as who to vote for, or whether to vote in favour of passing a bill. These are two examples of decisions that are obviously made by people occupying different roles within a political system. In this paper I focus on the political beliefs of citizens; so political beliefs in this paper can, unless stated otherwise, be limited to the class of beliefs directly relevant to the decision-making process of an individual citizen deciding who to vote for. ${ }^{4}$ Political beliefs can have either descriptive or normative content. A specific example of a descriptive political belief is the belief that the current Conservative government budget proposal will cut taxes for the wealthiest $10 \%$. An example of a normative political belief is the belief that the current Conservative government budget proposal should cut taxes for the wealthiest $10 \% .{ }^{5} \mathrm{We}$ can say that any political belief that meets the standards of knowledge (truth, justification, modal safety, etc.) is political knowledge.

A large amount of evidence has been amassed over the last 60 years (or more) that seems to imply that citizens of large representative democracies are decidedly not very good at acquiring political knowledge. Here are some quick examples from the US:

\footnotetext{
Moreover, it is worth noting that the vagueness of the definition fits with the idea that the boundaries of politics are themselves vague and broad. What counts as a political issue is in constant flux. Thanks to an anonymous referee for pressing this worry. Thanks to Jeroen de Ridder for helpful discussion.

${ }^{4} \mathrm{We}$ could also focus on questions about the political knowledge of other key members of political systems, such as members of the judicial system, members of the bureaucracy, and political delegates themselves.

${ }^{5}$ The focus in this paper will be on descriptive political beliefs. This is to simplify the discussion. Normative political beliefs raise a host of questions, including whether they are genuine beliefs (as opposed to conative states, or a hybrid of cognitive and conative states), and whether they can count as knowledge. See also fn.16.
} 
Much of the time, only a bare majority [of Americans] know which party has control of the Senate, some 70 percent cannot name both of their state's senators, and the majority cannot name any congressional candidate in their district at the height of a campaign (Somin 2013, 19).

A 2006 Zogby poll found that only 42 percent of Americans could even name the three branches of the federal government: executive, legislative, and judicial (Somin 2013, 19)

Opinions on the significance of political ignorance for theories about representative democracy differ radically. But there is a fair amount of consensus on the existence of political ignorance itself. A prominent sceptic about the very idea of representative democracy, Ilya Somin, claims: "The reality that most voters are often ignorant of even very basic political information is one of the better-established findings of social science. Decades of accumulated evidence reinforces this conclusion" (Somin 2013, 17). Meanwhile, Bruce Ackerman and James Fishkin — two writers who disagree with just about everything else Somin thinks—also claim: "If six decades of modern public opinion research has established anything, it is that the general public's political ignorance is appalling by any standard" (Ackerman \& Fishkin 2004). ${ }^{6}$

\footnotetext{
${ }^{6}$ There is by no means a complete consensus on the extent of political ignorance in large representative democracies. Gerry Mackie (2008) argues that there is a lot of room for debate about the conclusions that survey studies supposedly establish. For example, how the survey questions are posed may be a big factor. So may the context in which the questions are asked; for example, significant differences arise when participants are offered a dollar for their time, or given 24 hours to respond. Also, the way accuracy (of participant answers) is measured is crucial. What counts as a "correct" answer or "nearly correct" answer to
} 
A large number of studies go much further than suggesting people merely tend to have significant levels of false political beliefs (or lack of political beliefs altogether). These studies also seem to suggest that people have a strong tendency to be epistemically irrational and irresponsible in forming their political beliefs. That is to say, an extensive body of research indicates a significant level of biased belief formation and generally epistemically irresponsible habits of inquiry in the political context. Given the widely known phenomenon of cognitive bias in a range of our cognitive activities, this is hardly surprising.

Nevertheless, it will be helpful to have a few examples specific to the political context on hand. An extensive amount of research at the intersection of political science and cognitive psychology seems to show that:

- Most people tend to discuss political issues only with those who agree with them (Boutyline \& Willer 2017; Carlson \& Settle 2016; Gerber et al. 2012; Mutz 2006).

- This tendency is most pronounced among those most knowledgeable about and interested in politics (Caplan 2007; Mutz 2006).

- The same goes for selection of media sources (Garrett 2009; Iyengar \& Hahn 2009; Sunstein 2009).

certain questions can sometimes be a fuzzy thing to interpret. See Lupia and Prior (2008) for another helpful examination of conclusions from survey data. 
These are examples of empirical research supporting claims about a second negativeseeming epistemic phenomenon—one that may be causally related to the first, but which is also intuitively harmful in its own right (both practically and epistemically speaking). ${ }^{7}$

Moreover, the precise form such biases and habits of inquiry take in the political context appear to be exactly the sort of thing the intellectual virtues could help counter. That is, the above examples sound like cases of people failing to display the sorts of dispositions RVE is interested in theorizing about. Such experiments (and there are many others) seem to reveal a strong tendency in people to be precisely the opposite of, for example, "willing...to transcend a default cognitive standpoint in order to...take seriously a distinct cognitive standpoint" (Baehr 2011); or "disposed to recognize [their] own fallibility, and to recognize and value the epistemic abilities of others..." (Battaly 2014); or having the "proper ability to think for [themselves] and not be... improperly dependent on or influenced by others" (Roberts \& Wood 2007).

It seems that this is a prime example of an area in which we could use the help of RVE. Indeed, I've said that the political context looks like an especially good case for RVE to defend the ameliorative value of intellectual virtue. I turn now to argue that things are not quite so straightforward.

\section{RVE to the Rescue?}

Clear argumentative support for the ameliorative value of individual intellectual virtue is surprisingly elusive. To my knowledge, very little has been written specifically on the case

\footnotetext{
${ }^{7}$ Of course, the significance of these sorts of observations for our theories of representative democracy and democratic participation is also a subject of debate (Somin 2013; Caplan 2007; Christiano 2015; Lupia and McCubbins 1998).
} 
of political inquiry - but arguments that focus on the ameliorative value of intellectual virtue in the context of considerations about cognitive bias more generally are also relevant. Many specific examples of arguments from the literature merely conclude that the intellectual virtues could or might help correct for certain kinds of cognitive bias.

For example, Roberts and West (2015) claim: "We propose some ways that intellectual character virtues might help correct some of the 'biases and heuristics' that sometimes undermine our epistemic reliability" (Roberts \& West 2015, 2558 my emphasis). This is a far cry from arguing that the intellectual character virtues will do this work.

Samuelson and Church (2014) are bolder: "We identify the proper use of Type 2 cognitive processes and the habits of mind that attenuate biases as demonstrations of the virtue of intellectual humility" (Samuelson \& Church 2014). They focus on cognitive biases in general (targets include confirmation bias, hindsight bias, and the my-side bias (1102)) and examine four examples of behaviors and techniques that they claim help to mitigate epistemically harmful effects of these biases. ${ }^{8}$ These are: overt recourse to rulebased thinking, focusing on accuracy, focusing on accountability, and taking alternative perspectives. They point to a common theme in the empirical literature on the role of motivation in these de-biasing strategies, and take this to support the idea that they each count as examples of a manifestation of intellectual humility (because of RVE's standard motivational condition on the virtues). ${ }^{9}$

\footnotetext{
${ }^{8}$ They also explicitly acknowledge that there are worries about the effectiveness of each strategy (11031106).

${ }^{9}$ See Zagzebski (1996, Ch.2).
} 
Regardless of whether we call them cases of intellectual humility or something else, a key question is: in addition to requiring a certain kind of motivation, how are any of these de-biasing strategies really supposed to work? To be fair, Samuelson and Church get into some detail here (1103-1106). But it remains far from clear whether inducing and sustaining this sort of "intellectual humility" is something that can be achieved effectively at the individual level. Samuelson and Church appear to leave this an open question (2014, 1108).

There are well-known features of cognitive bias that should make us suspicious of the likelihood of success here. For a start, it's very difficult to know when one is making biased judgments in the first place. A growing body of research shows that people have a kind of bias blindspot, resulting in a conviction that one's own judgments are far less susceptible to bias than the judgments of others (Pronin 2007). The fact that, when people actually reflect on whether their judgments are biased or not, they tend to employ introspection to do so is one mechanism generating bias blindspot. The issue here is that biases operate at a subpersonal level, beyond the ken of introspection (Kahnemann 2003). Nathan Ballantyne (2015) helpfully outlines various other generators of bias blindspot, including the tendency to assume what has been called "naïve realism" (the idea that our experience of the world, others, and ourselves is veridical), and the motive of selfenhancement (i.e. our tendency to see ourselves in an overly positive light) (Ballantyne 2015, 150). It has also been shown that merely knowing about a particular bias, and that one is likely susceptible to it, is insufficient for reducing bias. As Kenyon points out, "I may very well allow that I am biased on many occasions while yet holding that this is not one of those occasions" (Kenyon 2014, 2535). We can regard this as a further manifestation 
of bias blindspot. "The blindspot in this type of case is the tendency for me to judge that the occasion at hand is always one of the unbiased ones" (2535). Most importantly, it has been shown that actively trying to de-bias oneself is often either completely ineffective, or worse, tends to further entrench one's biased judgment (Kenyon 2014; Ehrlinger, Gilovich \& Ross 2005). The feeling that we've tried our best to de-bias tends to lead to an increased confidence in the relevant judgment— but any ensuing sense that one is now free from bias is better explained by the in-principle opacity of bias.

A supporter of RVE might object that these observations merely show how difficult it is for individuals to contribute to the cultivation of their own intellectual virtues. They do not problematize the role that manifestations of individual intellectual virtue might play in knowledge acquisition. ${ }^{10}$ In terms of our distinction from section 2 , the objection would be that (at best) the above observations support the claim that RVE needs to be more causally non-agent-centered, as opposed to supporting the claim that RVE needs to be more constitutively non-agent-centered. In response, note that it is not clear why we should interpret these observations as speaking merely in favour of the former claim as opposed to the latter. In fact, my view is that they speak just as much in support of the latter claim. Take the opacity of cognitive bias. One might think that the relevant issue here is that the opacity of cognitive bias makes it hard to develop the habits of inquiry characteristic of someone who avoids certain cognitive biases. But my point is that the opacity of cognitive bias is an in-principle reason to think that, no matter how much an individual tries to be open-minded or intellectually autonomous, there are reasons to doubt that they will be capable, on their own, of effectively manifesting such virtues. If one wishes to be more

\footnotetext{
${ }^{10}$ Thanks to an anonymous referee for pressing this point.
} 
internalist about the concept of intellectual virtue, we can put the point a different way: no matter how open-minded, or conscientious, or intellectually autonomous one already is, there is reason to doubt that exercising these virtues can help one avoid thinking in cognitively biased ways in specific cases. The same point holds for observations concerning the inefficacy of knowledge of cognitive bias, and the tenacity of cognitive bias.

Beyond these generic points about the opacity and tenacity of cognitive bias, it will be useful to illustrate some more specific hurdles that can arise with an example. Consider, Tim Kenyon's (2014) work on false polarization bias. This is the tendency to perceive one's interlocutor in a disagreement as having more extreme views about the matter of disagreement than they in fact do. Kenyon helpfully examines various possibilities for debiasing in this regard. The one he identifies as most plausible involves counterfactually reasoning about possible arguments one might have had for the opposing view (Kenyon 2014). ${ }^{11}$ Kenyon notes that doing this on one's own is extremely difficult. Indeed, he suggests it is hopelessly unrealistic to expect such a de-biasing procedure to actually occur at the individual level, let alone succeed. For a start, a person's confidence in their own position may make it difficult for them to so much as imagine possible ways of arriving at a different conclusion. Alternatively, someone who is disposed to be self-consciously fallible will be prone to overdo the strategy, and find too many alternative paths likely. Finally, social pressures are apt to have an impact on individuals' willingness to engage in such counterfactual reasoning: one may fear the perception of being disloyal to a group, or worry that any concession one makes will be seen as a sign of weakness, for example (Kenyon 2014, 2542).

\footnotetext{
${ }^{11}$ Note the crossover here with Samuelson and Church's focus on "perspective taking."
} 
According to Kenyon, these are all reasons why dealing with false polarization bias is primarily a job for social institutions. In my view, the institutional proposal Kenyon floats isn't particularly realistic either. He focuses on the role officially appointed advisors can play in helping people engage in such counterfactual reasoning (think of specialists brought on board to assist a hiring committee). He even imagines an informalized version of this gradually becoming a part of everyday practice, one in which bystanders are routinely asked to play the role of advisor for parties to a dispute. Regardless, the basic point is well taken. It would not be surprising to learn that de-biasing oneself in this regard — simply by exercising one's intellectual virtue — is a worryingly difficult pursuit. ${ }^{12}$ Nor would it be surprising to learn that this specific example is representative of a general phenomenon.

Elizabeth Anderson goes a step further and argues that factors at a wider social level are sometimes quite demonstrably the primary, or even sole cause of the epistemic harm of particular biases. For example, she argues that "shared reality bias" is often epistemically neutral, and sometimes even epistemically useful. Shared reality bias is "the tendency of individuals who interact frequently to converge in their perspectives on and judgments about the world" (Anderson 2012). In addition to a variety of practical benefits, it can be epistemically useful for individuals engaged in joint-inquiry, insofar as it keeps them "on the same page". Anderson claims that "when groups of inquirers are segregated along the same lines that define group inequalities, the shared reality bias will tend to insulate members of advantaged groups from the perspectives of the systematically disadvantaged"

\footnotetext{
${ }^{12}$ In terms of my distinction in section 2, Kenyon's suggestion is that our investigation into de-biasing strategies should be constitutively non-agent centered.
} 
(Anderson 2012, 170). The upshot is the potential for what Fricker calls "hermeneutical injustice", a particular kind of epistemic injustice: claims made by members of the disadvantaged group may be difficult, if not impossible, to understand for members of the advantaged group. As a result, in contexts created by inequality-grounding group segregation — a structural phenomenon—shared reality bias becomes a vector for epistemic injustice (Anderson 2012, 170). The point here is simply that this is one way of revealing how making changes at the individual level is not necessarily what matters.

None of this settles the question of whether we should be focusing on intellectual virtue or elsewhere in a general ameliorative epistemology. But these points provide some support for the claim that focusing on intellectual virtue in an ameliorative epistemology is less tractable than we might at first have thought. I turn now to some positive examples of ways in which we could be focusing on non-agent-centered ways of promoting knowledge acquisition to reinforce this idea.

\section{Non-Agent-Centered Ways of Promoting Knowledge-Acquisition}

First, consider the enormous literature on "information shortcuts" (Christiano 2015; Mackie 2008; Popkin 1994; Robertson 1976). ${ }^{13}$ Information shortcuts, roughly, are bits and pieces of information that enable people to make the same decisions with respect to some set of options that they would if they were "fully informed" about the options. For example, research suggests that party identification is an information shortcut, in the sense that knowing which party a candidate is running for can enable a person to make the same

\footnotetext{
${ }^{13}$ Research on information shortcuts in the political context intersects with the "fast and frugal heuristics" literature in cognitive psychology (see Bishop 2000).
} 
decision about whether to vote for that candidate as they would if they knew a great deal about the candidate's track record, their policies, and the likely consequences of those policies. ${ }^{14}$ Other examples of information shortcuts frequently discussed in the literature include: retrospective evaluations of the economy, comparing the likeability of one candidate over another, and relying on opinion leaders. ${ }^{15}$

Information shortcuts aren't merely relevant to politics: they play an indispensable role in any society that relies on a specialized division of cognitive labor (Christiano 2015, 257). Consider the question of whether the food you just bought from your local supermarket is safe to eat. Rather than doing an elaborate safety check yourself, you (typically) rely on the very fact that the food was sold at your supermarket in deciding whether it's safe to eat. As Christiano memorably puts it, an ideal of citizenship according to which "every citizen should be informed in a way that is independent of how others are informed... is spectacularly irrelevant for all societies that have moved beyond the huntergatherer stage" (Christiano 2015, 258).

Of course, a lot of debate surrounds the very idea of an information shortcut, and more specifically what effective information shortcuts in the political domain might look like. My intention here isn't to settle this debate. Rather, it is to suggest that information shortcuts are a crucial element to take seriously in understanding the role of knowledge in

\footnotetext{
${ }^{14}$ There is of course controversy over the extent to which party identification serves as an effective information shortcut. My point isn't to take a stand on whether party identification is an effective information shortcut; I merely use it as an example to illustrate a plausible general idea.

${ }^{15}$ Each of these examples comes with important qualifications. According to Sniderman et al (1991), for example, the likability heuristic works only for relatively sophisticated voters: "a requirement of the effective use of the heuristic is precisely to have organized, in a politically coherent way, both one's feelings and one's beliefs" (1991, 24). Getting into the details of any one specific (putative) information shortcut would take us too far afield.
} 
a representative democracy — an element that implies the cognitive burden of democratic participation on individual agents is less significant than it might at first appear.

One way in which we could do more than theorize about intellectually virtuous character traits, then, is by addressing epistemological questions about what works as a reliable guide to what particular individuals would decide under fuller informational conditions. We could also try to gain a better understanding, from an epistemological perspective, about the conditions under which particular shortcuts count as appropriately employed. This latter project would require a more in-depth account of the way in which multiple epistemic demands of individuals' practical lives interact, and an account of the respective value of meeting those demands. We could also potentially even incorporate insights from RVE by developing characterizations of virtuous uses of information shortcuts. This is certainly no small set of tasks. But that doesn't mean that carrying it out is not a more realistic and effective way of doing ameliorative epistemology.

In what way is this proposal non-agent-centered? Isn't the focus primarily on individuals and their ability to deploy heuristics to arrive at informed decisions? The proposal is non-agent-centered in the sense that it encourages greater focus on the way environmental and structural factors can do much of the work in enabling individuals to make informed decisions. For example, when it comes to the information shortcut of party identification, a significant part of the epistemic work is done by the party system itself. In this way, the epistemology of information shortcuts can be constitutively non-agentcentered - it involves looking at the role that structural elements of institutions and other social relations themselves play in promoting knowledge acquisition in individuals. 
As the Christiano quote intimates, many of our political beliefs come from the word of others (whether directly from individuals, or through information produced by collectives, such as a party flyer, etc.). ${ }^{16} \mathrm{~A}$ big issue here is that people of course need to know who to trust when it comes to acquiring political beliefs. This is true of any testimonial exchange. But it is especially true in the political context, given that it is particularly hard to determine the character (i.e. how honest, reliable, etc.) and interests of individuals/collectives providing political information.

It is hard to see how some degree of individual intellectual virtue is not important here. But when it comes to the ameliorative question at hand, there are other focal points worth noting. For one, we can focus on ways at the level of institutions to make it easier for people to acquire political information from others. To focus on just one example, Arthur Lupia and Matthew McCubbins (1998) have developed a sophisticated approach to the role of institutions in political knowledge acquisition. They argue that "external incentive altering forces," such as penalties for lying, likelihood of verification, and observable costly effort, allow people to more easily infer whether an information source is trustworthy or not, without exercising much judgment about the character or interests of the source in question. Institutions can provide these forces, and as such provide ways of promoting knowledge acquisition without focusing primarily on the intellectual character traits/abilities of individual agents. Let me explain in a bit more detail.

\footnotetext{
${ }^{16}$ This seems especially true given our restriction to "descriptive" political beliefs. It's less clear whether and to what extent our normative political beliefs come from the word of others. Consider, for example, the debate about whether moral knowledge can be acquired by testimony. Delving into this interesting question would take us too far afield.
} 
The simplest example — in a non-political context — of what Lupia and McCubbins have in mind is the penalty of perjury in a court of law. Members of the jury know that, other things being equal, most people take such a penalty seriously. The penalty acts as an incentive not to lie. As a result, other things being equal, members of the jury can conclude with a fair degree of confidence that whomever it is that's testifying in the court is telling the truth. This is the case regardless of what they know about the testifier's character, or what the testifier's general interests relative to the case are. Similarly, courts of law provide a likelihood of verification - jurors and testifiers alike know that whatever the testifier says in court will be subject to verification (through cross-examination and the collection of evidence). This significantly reduces the testifier's incentive to say anything verifiably false. Thus, likelihood of verification in this context is an external incentive altering force enabling jurors to trust a testifier, regardless of what they know about the testifier's character, or what the testifier's general interests relative to the case are.

In the political context, one traditional function of the media, Lupia and McCubbins' would say, is to provide the external incentive altering force of likelihood of verification. How well various media outlets play this role, and whether or to what extent they are regarded as doing so by citizens, is of course a large question in its own right. But the basic point for present purposes is that institutions providing a likelihood of verification increase the extent to which citizens can trust an information source without knowing much about the interests or general character of the source. Penalties for lying in the broader political context are of course very different from the simple case of perjury in a court of law. But there are natural penalties built into certain features of democratic politics: being revealed to be a liar usually damages one's reputation, and can hurt one's chances of being 
re-elected, for example. Again, the basic point is that institutions providing such penalties increase the extent to which citizens can trust an information source without knowing much about the interests or general character of the source. ${ }^{17}$

Another way, then, in which we could do more than theorize about intellectually virtuous character traits is by developing an epistemological account of what works as an external incentive altering force, and also what sorts of institutions can provide them (courts of law, advertising regulations, etc.). This would also seem to require theorizing about the conditions under which instances of informational exchange count as epistemically appropriate in such institutionally constrained contexts. We could further incorporate insights from RVE by developing characterizations of intellectually virtuous inquiry in the context of institutionally facilitated external incentive altering forces. This is

\footnotetext{
${ }^{17}$ The notion of observable costly effort, and the way this can serve as an external incentive altering force, is a bit more complex, and raises a host of questions it would take us too far afield to get into here. But the basic idea is as follows. If as a group we face a decision about how we want to organize ourselves (as in the case of an election), from the fact that someone is putting a lot of effort and resources into making a proposal for how we might organize ourselves, other things being equal, we can infer that their proposal differs in some significant way from the status quo. Otherwise, to put it roughly, why put significant effort into making the proposal? The key point is that we can infer this without knowing anything about the contents of the proposed change, or any of the specific ways in which it differs from the status quo. So, if one is happy with the status quo, and observes someone making a costly effort, other things being equal one can make an effective decision about whether to accept the proposal on this basis. Electoral institutions can have such effects. For example, campaign-finance disclosure laws require that party campaigns, as well as lobbyists, identify in a publicly available way all significant financial contributors and how much was contributed by each. According to Lupia and McCubbins, this is a way of making transparent the observable costly effort that a party - and the specific special interest groups supporting it - are making in the service of getting their message out there. "If a person is reasonably happy with the status quo, and would thus like to see only a small change in policy, and if she observes the sponsor of a ballot initiative spending several million dollars to affect the election, then, without any further information, she can infer that the initiative proposes a very large change in the status quo and that she should oppose it" (Lupia \& McCubbins 2000, 60).
} 
perhaps an even more daunting task than adequately developing our understanding of information shortcuts within an RVE. But, again, that does not mean that carrying it out is a not more realistic and effective way of doing ameliorative epistemology.

\section{Political Inquiry and RVE}

Taking stock, I've suggested that there are reasons to be pessimistic about the ameliorative value of individual intellectual virtue in the political context. I've also explored two examples of non-agent-centered ways of promoting knowledge acquisition in this context.

I think this reveals ways in which RVE focuses too narrowly on individual virtue in its ameliorative aims. But all of this raises an important question. In what way, exactly, are considerations about political inquiry relevant to an evaluation of RVE? After all, RVE is a theory of human cognition in general. It doesn't aim to provide an account of the way people think about politics, or any other topic in particular. Moreover, one might think that there's something unfair about holding a general theory up to scrutiny vis-à-vis what seems like a fairly special sort of case. Perhaps something about the very nature of politicswhether it's the heated emotional issues involved, or the role of values in shaping people's views - makes it particularly hostile to virtuous conduct of any kind.

There are at least two main reasons why the case of political inquiry is relevant, and interesting to focus on, in an assessment of RVE. First, the context of politics provides an area of inquiry that it seems RVE has been especially interested in theorizing about. There are many areas of inquiry a better understanding of which does not seem to require theorizing about person level intellectual virtues. For example, consider finding out what's in the fridge. Cases of simple perceptual knowledge have been a major sticking point for 
RVE in the context of questions about the relationship between intellectual virtue and knowledge. Are the intellectual virtues necessary for knowledge? Are they sufficient? (Greco 2010, Sosa 2015; cf. Zagzebski 1996, Baehr 2011). The general response on behalf of RVE has been to claim that the intellectual virtues are only necessary for-or especially salient in explanations of the acquisition of - "high-grade" kinds of knowledge.

In his discussion of high-grade knowledge, Jason Baehr (2011) provides three cases — involving a biologist, detective, and historian respectively — as paradigm cases of knowledge that require the exercise of intellectual virtue:

In these scenarios, reaching the truth is not simply or even primarily a matter of having good eyesight, a good memory, or making valid logical inferences. Rather, the individuals in question reach the truth because they exhibit certain attitudes or character traits. These traits seem to account most saliently for or to best explain why the individuals form true beliefs. The biologist, for example, discovers why the relevant bird species has altered its migratory course on account of his patient, focused inquiry and his refined powers of observation and discrimination. The reporter uncovers a corporate scandal because he is intellectually courageous and autonomous. And the historian accepts and acknowledges a major error in her work because of her intellectual openness, honesty, humility, and general love of truth (Baehr 2011, 54).

Political knowledge is not the sort of thing that we can acquire simply, or even primarily, through good eyesight, good memory, or making valid logical inferences. On the face of 
it, it seems to be much more sophisticated than that. It seems to require considering various viewpoints, weighing evidence for and against certain claims, not jumping to conclusions, and so on. ${ }^{18}$ Political knowledge seems like a paradigm case of what RVE theorists would regard as high-grade knowledge. Again, this is exactly the sort of area RVE has tended to focus on as a result of disputes or disagreements with more traditionally-minded epistemologists. In other words, it would seem that the sort of knowledge RVE theorists themselves claim RVE is most important for is the kind of knowledge precisely at stake here. So it is particularly interesting and important in a general assessment of RVE.

Secondly, the example of political knowledge is just one instance of a much more general phenomenon. Namely, it is an example of a domain of inquiry in which agents tend to feel they have little incentive to make a cognitive effort. ${ }^{19}$ Note that few theorists claim that people are politically ignorant because they are generally stupid or lazy. Rather, many agree with the Anthony Downs' (1957) idea that political ignorance is instrumentally rational. In particular, according to Downs (and others) the rationality of political ignorance is an upshot of the nature of voting in a representative democracy with millions of voters. It's an upshot of the fact that the chances of your vote being a deciding factor in an election

\footnotetext{
${ }^{18}$ The previous section's discussion of the role of non-agent-centered factors in the acquisition of political knowledge potentially mitigates the extent to which this really is the case. Moreover, some of the examples of political ignorance from earlier (7) may seem like failures of basic cognitive faculties (such as memory), as opposed to anything "high grade". But the claim here need not be that all political knowledge is highgrade. As long as political knowledge generally requires more than basic use of one's innate cognitive faculties (such as sense perception, or memory), my point goes through. This seems very plausible. RVE theorists would themselves likely agree with this description of political knowledge.

${ }^{19}$ On the face of it, political knowledge is indeed a valuable kind of knowledge and people of course have an incentive to acquire it (not least because of its role in citizens' ability to hold elected officials to account, for example). This is why I restrict the phenomenon at issue to cases of perceived low incentive to make a cognitive effort.
} 
or referendum are near zero. The idea is that this has a significant impact on your incentive to get informed about whatever it is you are voting on. ${ }^{20}$

Regardless of whether political knowledge is actually valuable, and how much cognitive effort achieving it actually requires, contexts of perceived low incentive for cognitive effort tend to arise when agents feel that beliefs they form about a particular matter have little chance of affecting their practical life, or the practical lives of others.

To illustrate with a contrast, consider making a big purchase. Perhaps it's a new home, or a new car. People tend to think (however implicitly) that what they believe about factors relevant to a big purchase has a high likelihood of making an impact on their practical lives (consider factors such as which car gets the best mileage, or which house has the better property value, etc.). So, they perceive themselves as having a high incentive to make a cognitive effort. Other examples of perceived low incentive for cognitive effort contexts might be forming beliefs about religion, basic science, world geography, or history (see Somin 2013, 77 for interesting stats on ignorance in these domains). If that is correct, then inquiry with a perceived low incentive for cognitive effort is a pervasive phenomenon.

What's significant about such contexts is that, in the absence of an incentive to make a cognitive effort, they are contexts in which biased cognition and other epistemically harmful modes of inquiry are apt to creep in. It is plausible that a perception of low incentive to make a cognitive effort is a core part of the explanation of why, in the political

\footnotetext{
${ }^{20}$ This is contentious and has generated a lot of debate in its own right. For example, Mackie (2008) argues that Downs' idea presupposes a mistaken model of why people vote in the first place. Mackie argues for a "contributory model," according to which the aim of voting isn't merely to get someone to win, but also to show that whomever you're voting for, even if they lose, has a certain mandate behind them. Regardless, if true, Downs' idea would provide a pretty compelling explanation of the amount of political ignorance studies seem to reveal.
} 
context, people tend to lack significant amounts of knowledge/concern for epistemically appropriate ways of forming beliefs. If political inquiry is just one example of a domain in which this phenomenon is at work, then any lessons we learn in this case may apply to a wide range of examples of human inquiry. As such, the case of political inquiry is particularly interesting and important in a general assessment of RVE.

\section{Conclusion}

I am not suggesting that the intellectual virtues have no role in ameliorative epistemology. There is no reason to think any one of the proposals considered above must be pursued at the expense of any of the others. Indeed, there is good reason to think that a challenge such as promoting political knowledge acquisition must be met on multiple fronts. ${ }^{21}$ Perhaps the best way for RVE to respond to the claim that the political context threatens to expose RVE as focusing too narrowly on individual virtue is by embedding the mapping project within non-agent-centered epistemic efforts. I've given two illustrations of the sort of thing I have in mind. There is much more room for thinking about how such developments might work, and that is a worthwhile project.

\section{References}

Ackerman, B. \& Fishkin, J. 2007. Deliberation Day.

Anderson, E. Epistemic justice as a virtue of social institutions. Social Epistemology, 26:163-173.

\footnotetext{
${ }^{21}$ John Christman has some insightful points about how the legitimacy of structural change plausibly requires change at the individual level (Christman 2012).
} 
Baehr, J. Forthcoming. Intellectual virtues, critical thinking, and the aims of education. In the Routledge Handbook of Social Epistemology, P. Graham, M. Fricker, D.Henderson, N. Pedersen, and J. Wyatt (Eds.), Routledge. 2015. (ed.) Intellectual Virtues and Education: Essays in Applied Virtue Epistemology. New York: Routledge.

2011. The Inquiring Mind. Oxford: OUP.

Ballantyne, N. 2015. Debunking biased thinkers (including ourselves). Journal of the American Philosophical Association, 1: 141-162.

Battaly, H. 2016. Developing virtue and rehabilitating vice: worries about self-cultivation and self-reform. Journal of Moral Education, 45:207-222.

2014. Varieties of epistemic vice. In Jonathan Matheson \& Rico Vitz (eds.), The Ethics of Belief, Oxford: Oxford University Press.

2013. Detecting epistemic vice in higher education policy: epistemic insensibility in the seven solutions and the REF. Journal of Philosophy of Education, 47: 263-80.

Bishop, M. 2000. In praise of epistemic irresponsibility: how lazy and ignorant can you be? Synthese, 122: 179-208.

Boutyline, A. \& Willer, R. 2017. The social structure of political echo chambers: variation in ideological homophily in online networks. Political Psychology, 38: 551-569.

Caplan, B. 2007. The Myth of the Rational Voter. Princeton: Princeton University Press.

Carlson, T. \& Settle, J. 2016. Political chameleons: an exploration of conformity in political discussions. Political Behavior, 38: 817-859. 
Carter, A. \& Gordon, E. 104. Openmindedness and Truth. Canadian Journal of Philosophy 44: 207-224.

Carter, A. \& Pritchard, D. 2017. Epistemic situationism, epistemic dependence, and the epistemology of education. In A. Fairweather and M. Alfano (eds.), Epistemic Situationism, Oxford: Oxford University Press.

Cassam, Q. 2016. Vice epistemology. The Monist.

Christiano, T. 2015. Voter ignorance is not necessarily a problem. Critical Review, 27:253-269.

Christman, J. 2012. Comments on Elizabeth Anderson, 'Epistemic Justice as a Virtue of Social Institutions'. The Social Epistemology Review and Reply Collective.

Downs, A. 1957. An Economic Theory of Democracy. New York: Harper.

Ehrlinger, J., Thomas, G., \& Lee, R. 2005. Peering into the bias blind spot: people's assessments of bias in themselves and others. Personality and Social Psychology Bulletin, 31:680-92.

Fricker, M. 2007. Epistemic justice. Oxford: OUP.

Garrett, R. K. 2009. Echo chambers online? politically motivated selective exposure among internet news users. Journal of Computer-Mediated Communication, $14: 265-85$.

Gerber, A. et al. 2012. Disagreement and the avoidance of political discussion: aggregate relationships and differences across personality traits, American journal of Political Science, 56: 849-74.

Greco, J. 2010. Achieving Knowledge. Cambridge: CUP. Haidt, J. 2012. The Righteous Mind. New York: Vintage. 
Haslanger, S. 2015. Distinguished lecture: social structure, narrative and explanation.

Canadian Journal of Philosophy 45: 1-15.

Kahneman, Daniel. 2003. A perspective on judgment and choice'. American Psychologist, 58:697-720.

Kenyon, T. 2014. False polarization: debiasing as applied social epistemology. Snythese, 191: 2529-2547.

Kidd, I. J. 2018. Epistemic corruption and education. Episteme, 1-16.

2015. Educating for intellectual humility. In J. Baehr (ed.), Intellectual Virtues

and Education: Essays in Applied Virtue Epistemology, New York, NY:

Routledge.

Kwong, J.M.C. 2017. Is open-mindedness conducive to truth? Synthese. 194:5.

Iyengar, S. \& Hahn, K. S. 2009. Red media, blue media: evidence of ideological selectivity in media use. Journal of Communication, 59:19-39.

Lupia, R. \& McCubbins, M. 1998. The Democratic Dilemma: Can Citizens Learn What They Need to Know? Cambridge: CUP.

2000. The institutional foundations of political competence. In Elements of Reason, Lupia, A., McCubbins, M., \& Popkin, S. (eds.). Cambridge: CUP.

Lupia, A. \& Prior, M. 2008. Money, Time, and Political Knowledge: Distinguishing Quick Recall and Political Learning Skills.

Mackie, G. 2008. Rational ignorance and beyond. In Collective Wisdom: Principles and Mechanisms, ed. Jon Elster and Hélène Landemore. Cambridge: CUP.

Madison, B.J.C. 2017. Is open-mindedness truth conducive? Synthese. 1-13. 
Montmarquet, J. 1993. Epistemic Virtue and Doxastic Responsibility, Lanham: Rowman and Littlefield.

Mutz, D. 2006. Hearing the Other Side: Deliberative Versus Participatory Democracy. Cambridge: CUP.

Popkin, S. 1994.The Reasoning Voter. Chicago: University of Chicago Press.

Pritchard, D. 2015. Intellectual virtue, extended cognition, and the epistemology of education.’ In J. Baehr (ed.), Intellectual Virtues and Education: Essays in Applied Virtue Epistemology, New York, NY: Routledge

2015. Epistemic dependence. Philosophical Perspectives.

Pronin, E. 2007. Perception and misperception of bias in human judgment, Trends in Cognitive Science, 2: 37-43.

Roberts, R.C. \& West, R. 2015. Natural epistemic defects and corrective virtues. Synthese, 192: 2557-2576.

Roberts, R. C., \& Wood, W. J. 2007. Intellectual Virtues: An Essay in Regulative Epistemology. Oxford: Clarendon Press.

Robertson, D. 1976. Surrogates for party identification in the rational choice framework. In Party Identification and Beyond: Representations of Voting and Party Competition, ed. Ian Budge, et al. London: Wiley

Rowbottom, D. 2011. Popper's Critical Rationalism: A Philosophical Investigation. New York: Routledge.

Samuelson, P.L. \& Church, I. 2014. When cognition turns vicious: heuristics and biases in light of virtue epistemology. Philosophical Psychology, 28: 1095-1113. 
Simion, M., Kelp, C., Boult, C. \& Schnurr, J. Forthcoming. Moral virtues with epistemic content. In C. Kelp \& J. Greco (eds.), Virtue-Theoretic Epistemology: New Methods and Approaches, Cambridge: CUP.

Somin, I. 2013. Democracy and Political Ignorance. Stanford University Press.

Sosa, E. 2015. Judgment and Agency. Oxford: OUP.

Sniderman, P., Brody, R., \& Tetlock, P. 1991. Reasoning and Choice: Explorations in Social Psychology. Cambridge: CUP.

Tanesini, A. 2016. Teaching virtue: changing attitudes. Logos \& Episteme, 7:503-527.

Veitch, J. A., \& McColl, S. L. 2001. A critical examination of perceptual and cognitive effects attributed to full-spectrum lighting. Ergonomics, 44: 255- 279.

Watson, L. 2015. Why should we educate for inquisitiveness? In J. Baehr (ed.), Intellectual Virtues and Education: Essays in Applied Virtue Epistemology, New York, NY: Routledge.

Zagzebski, L. 1996. Virtues of the Mind: An Inquiry into the Nature of Virtue and the Ethical Foundations of Knowledge, Cambridge: CUP. 